\title{
THE EFFECT OF ANTIBIOTICS ON THROMBOPLASTIN GENERATION
}

\author{
BY \\ W. N. BELL AND H. G. ALTON \\ From the Department of Medicine, University of Cambridge
}

(RECEIVED FOR PUBLICATION SEPTEMBER 15, 1954)

The effect of antibiotics on the blood coagulation mechanism has attracted the attention of many workers in various countries. Investigations have mostly been based on changes in the clotting time before, during, and after administration of the drugs in vivo (Parker and Wright, 1952; Galt and Hunter, 1950; Miller and Bass, 1952; Casassa, 1952; Macht, 1952 ; and many others). This approach has led to confusing and conflicting reports, and to the indictment on these grounds of almost every antibiotic at various times. Florey and Jennings (1949) remarked that

"In view of the difficulty of making reliable and consistent estimates of coagulation time .... it is justifiable to accept reports of abnormality with reserve until they are fully confirmed, especially as little or nothing to bear them out has been reported from among the thousands of patients treated in the clinic."

In addition to the effect on the clotting time, a few reports have appeared in which the effect on other tests has been studied (e.g., heparin titration and one-stage prothrombin times). No attempt appears to have been made otherwise to localize the site of action, resulting in an observed clotting time change, within the coagulation mechanism. The difficulty in interpreting the findings in the literature caused us to attempt a fresh approach to the problem by means of newer coagulation techniques. The possibility of thrombosis or haemorrhage due to, or aggravated by, these drugs may have a bearing on their clinical use ; our interest has been especially in connexion with the effect that they might have in patients already suffering from a haemorrhagic condition, e.g., acute leukaemia with thrombocytopenia, haemophilia, etc.

\section{Methods}

A modified Lee-White clotting time technique was used with siliconized glass tubes. Venous blood, collected with as little trauma as possible, was placed in $1 \mathrm{ml}$. quantities in three clean, dry, siliconized tubes,
$75 \times 8 \mathrm{~mm}$. at $37^{\circ} \mathrm{C}$. Beginning after three minutes, the first tube was tilted at 30-second intervals until clotting occurred. The second tube was then tilted at the same intervals until it, too, clotted; finally, the third tube was similarly tilted, and its time recorded as the clotting time for the test in question. With this method, our normal range is 13-18 minutes. Siliconized tubes were used to magnify any changes which might occur in the clotting time, and also to eliminate a foreign surface effect as far as possible. In the case of haemophilic blood, non-siliconized tubes were used, because of the length of time otherwise involved. For testing of an antibiotic in vitro, $0.1 \mathrm{ml}$. of the desired concentration of the drug in $0.85 \%$ saline was placed in each of one set of tubes, and $0.1 \mathrm{ml}$. of saline alone in another set as control; the blood was gently agitated with both solutions before being allowed to clot. This probably explains why our normal (silicone) clotting times are somewhat shorter than those generally reported in the literature.

The one-stage prothrombin time method of Quick was used to exclude changes in the prothrombin complex.

Prothrombin consumption was measured by obtaining the serum one-stage prothrombin time one hour after clotting had occurred (the clotting time test-tubes could be used for this). Human fibrinogen at a concentration of 7 to $9 \mathrm{mg} . / \mathrm{ml}$. in borate buffer was employed, and the minimal time for normal blood was 25 seconds (30 seconds when non-siliconized glass is used).

The thromboplastin generation test of Biggs and Douglas (1953) was modified by the use of a brain extract, as previously described by Bell and Alton (1954), in place of the platelet suspension. By the use of this extract, and with two workers, we have found our normal " peak" times to be $10 \pm 1$ seconds, with an accuracy of \pm 0.5 second. Ten seconds was arbitrarily chosen as representing $100 \%$ thromboplastic activity. To test the effect in vitro of a given antibiotic on thromboplastin generation, $0.3 \mathrm{ml}$. of $0.025 \mathrm{M}$. calcium chloride solution was added to an incubation mixture containing in each case a 1 in 100 dilution of the brain extract, a 1 in 5 dilution of normal "alumina plasma," a 1 in 10 dilution of normal serum, and the required concentration of the selected antibiotic. At 1-minute intervals $0.1 \mathrm{~m}$. of this incubation mixture and $0.1 \mathrm{ml}$. of the $\mathrm{CaCl}_{2}$ solution were simultaneously added to $0.1 \mathrm{ml}$. volumes 
of normal plasma at $37^{\circ} \mathrm{C}$., and the clotting times noted. All results were read from the same dilution curve in terms of percentage thromboplastic activity of the saline control which was run before and after each set of tests.

\section{Results}

In Vitro.-Fig. 1 shows the results obtained when various antibiotics were added to the thromboplastin generation incubation mixture in varying concentrations; these were selected to cover adequately the usual therapeutic levels used clinically. From these results, it would appear that oxytetracycline (terramycin) may augment thromboplastin generation slightly, penicillin has no significant effect, whereas the other antibiotics (especially aureomycin) appear to decrease thromboplastin generation to a greater or less extent. These effects appear with concentrations falling within the range of therapeutic levels. Although not shown, magnamycin produced no significant effect.

It was found that the effect of $0.1 \mathrm{mg} . \mathrm{ml}$. of aureomycin could be partly reversed by increasing the concentration of the alumina plasma five times
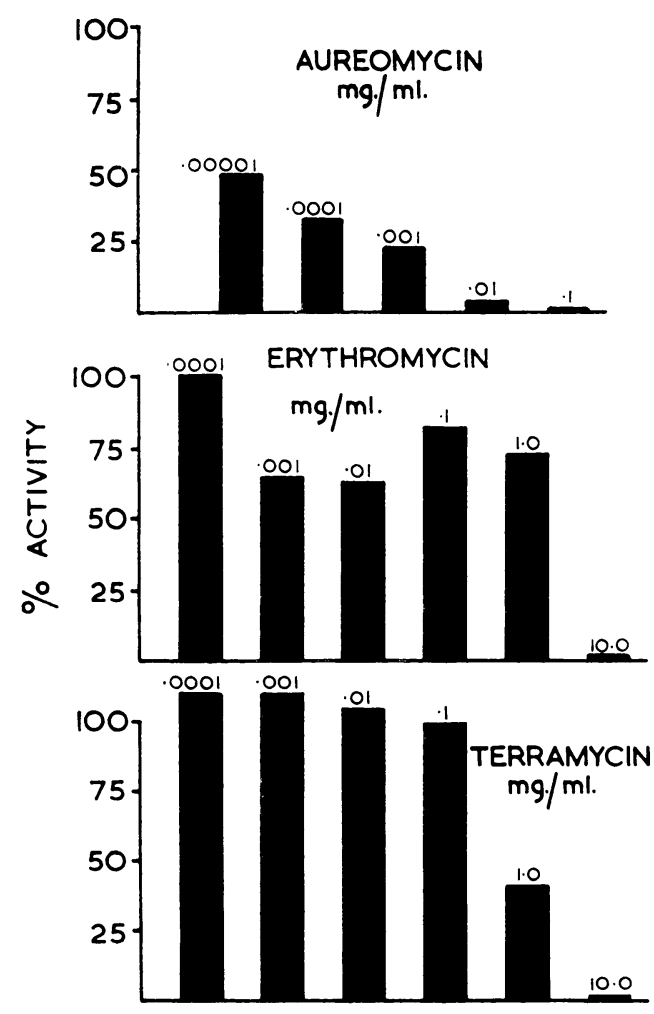

FIci. 1.--Effect in vitro of antibiotics in varying dose on thromboplastin generation. (i.e., using it undiluted), and completely reversed by $\frac{0}{\vec{\sigma}}$ increasing that of the serum 10 times (undiluted). Therefore it could be postulated that the drug was decreasing thromboplastin generation by rendering ineffective some factor present in serum, and also $\frac{}{0}$ in alumina plasma to a lesser extent, at a critical $\frac{\bar{\sigma}}{\bar{n}}$ level. One known factor which would seem to $\vec{\nabla}$ fulfil these criteria is the Christmas factor (P.T.C.).

In Vivo.-The results of administering four anti- $\vec{D}$ biotics to three normal controls are shown in Fig. $2: \stackrel{\circ}{\circ}$ the same normal subjects were used for each study. $\vec{\omega}$ The tests were carried out in the non-fasting state, as an approximation to ordinary clinical conditions:용 however, in some cases, the experiment was repeated 0 in the fasting state, with much the same results. ? All tests were performed immediately before, and $\vec{\omega}$ three and a half hours after, administration of the drug. In general, these results supported those of the tests in vitro. To be considered significant, all $\vec{z}$ the normals had to show the same trend to a greater or lesser extent. The lack of significant $\vec{\theta}$ change in the one-stage prothrombin time was of considered as evidence that no appreciable change or
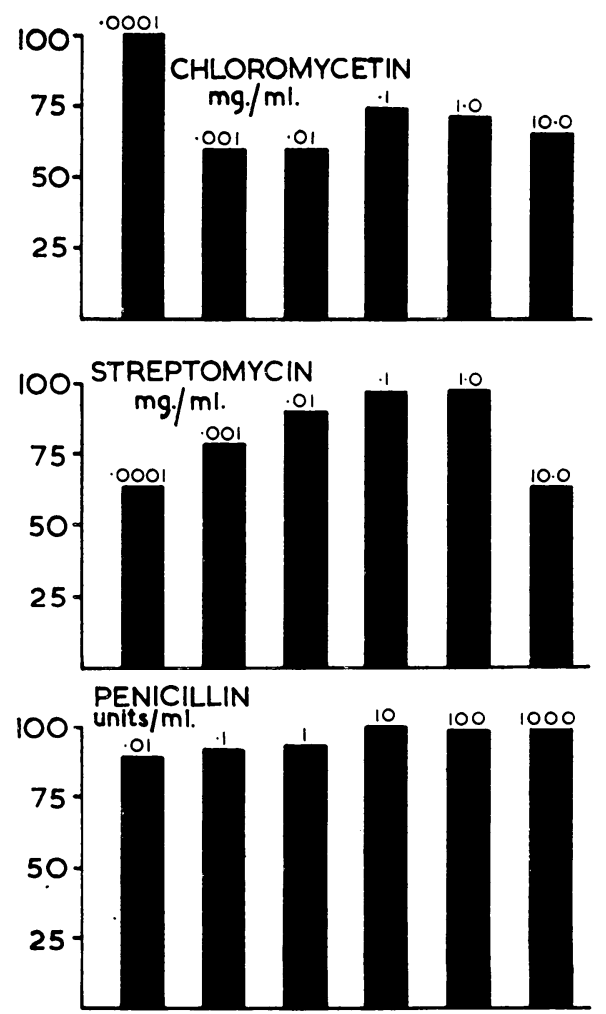
was occurring in the prothrombin, Factor V, Factor VII, or fibrinogen levels. The clotting time varied directly with the prothrombin consumption, suggesting that the site of action was at the level of formation of thromboplastin.

An attempt was made to throw more light on the factor involved by studying the changes in the thromboplastin generation test. When 1 in 10 dilutions of pre- and post-administration sera were compared, no significant difference could be noted. When the undiluted sera were used, the post-administration serum showed a significant decrease in activity (Fig. 3). A 50\% dilution of this serum with normal undiluted serum caused complete correction, as did undiluted haemophilic serum (which corrected even more than did the normal). However, a $50 \%$ mixture of postadministration serum and Christmas disease serum did not correct the defect. This finding served to strengthen

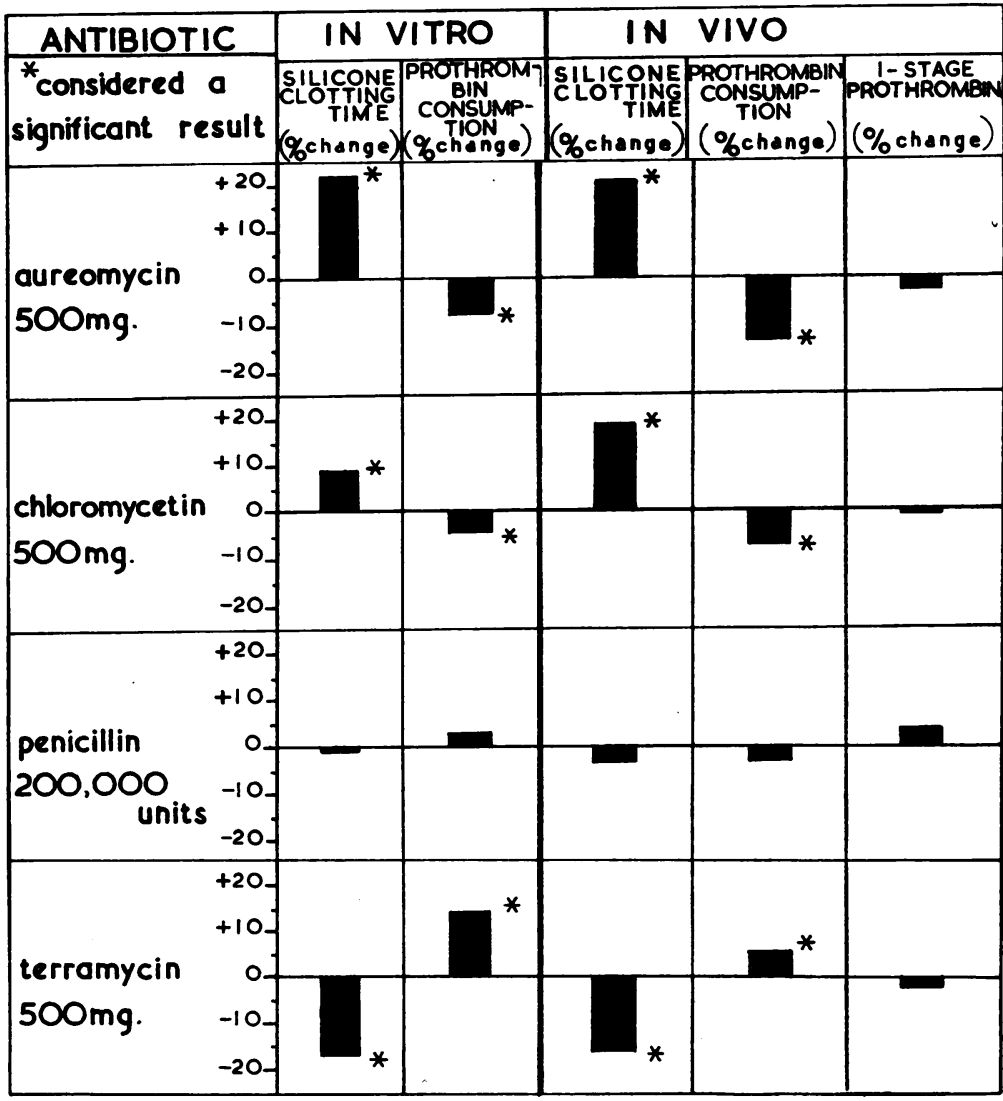

FIG. 2.-Effects in vitro and in vivo of various antibiotics on the normal coagulation mechanism.
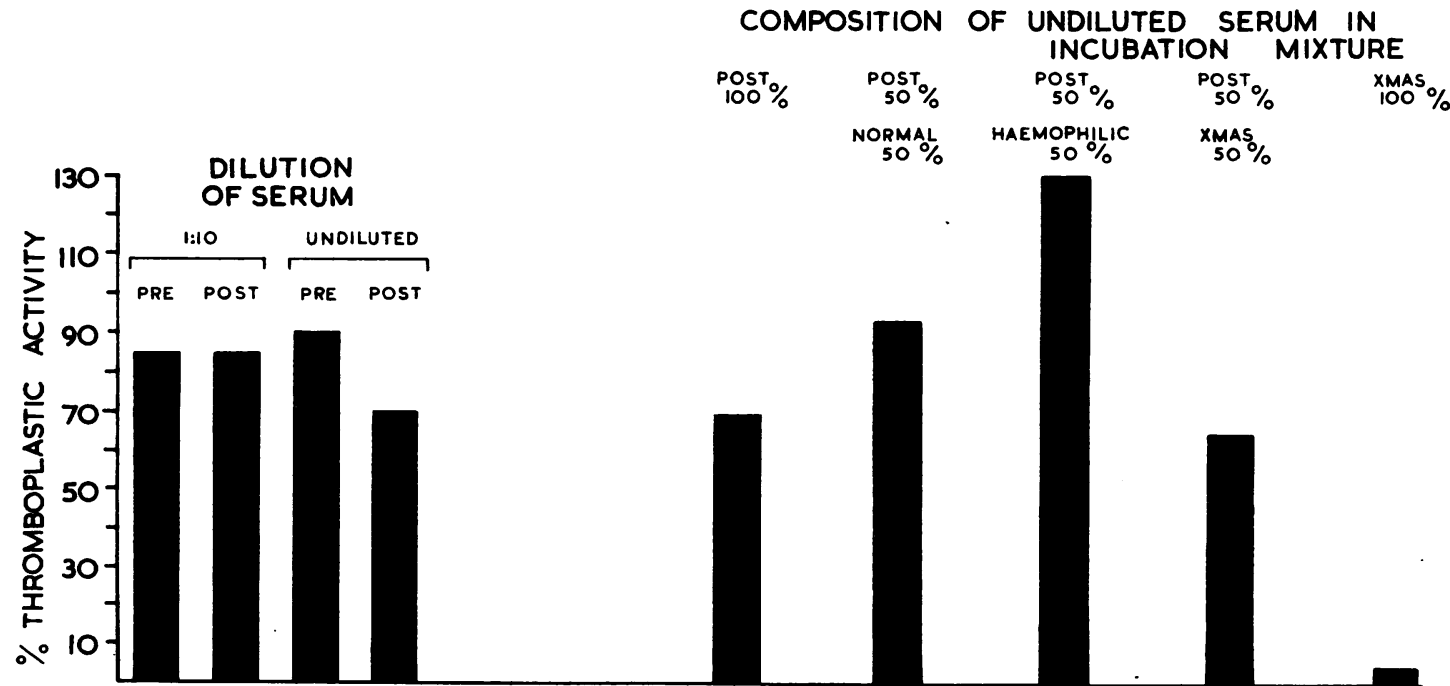

Fig. 3.-Defect in undiluted serum four hours after ingestion of $500 \mathrm{mg}$. aureomycin and its correction by various sera. 


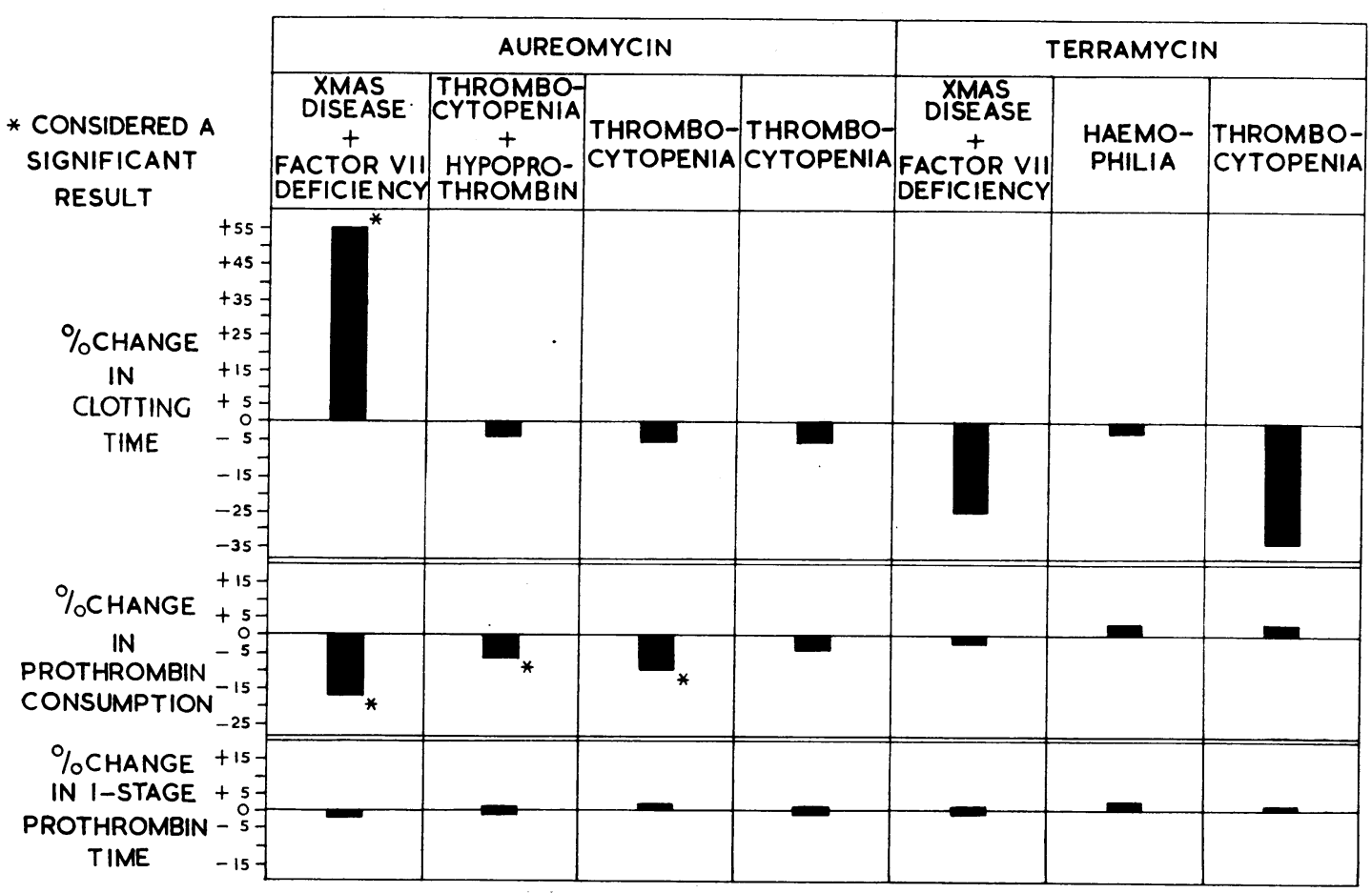

FIG. 4.-Effect of aureomycin and, terramycin pin vivo in bleeding states.

our conjecture that aureomycin may act by reducing the effective level of Christmas factor in the blood. Similar results, to a less marked extent, were found with post-administration serum in the case of chloramphenicol (chloromycetin).

Finally, because of our interest in the effect of these drugs on patients with haemorrhagic disorders, we gave $500 \mathrm{mg}$. of aureomycin and of terramycin to patients with thrombocytopenia, haemophilia, and one with Christmas disease combined with Factor VII deficiency (Fig. 4). Terramycin had no significant effect in any of these patients, and the slight increase in thromboplastin generation noted in the normals could not be demonstrated. Aureomycin again produced a decrease in thromboplastic activity, as judged by the prothrombin consumption test. Of particular interest is the effect in the patient with the combined Factor VII and Christmas deficiency. The unchanged one-stage prothrombin time and Factor VII determination showed that aureomycin apparently does not affect Factor VII. The significant aggravation of his Christmas disease state is a further piece of evidence in favour of the suggestion that it is by way of the Christmas factor that aureomycin affects the coagulation mechanism.

\section{Discussion}

Biggs, Douglas, and Macfarlane (1953) have shown that the components necessary for the generation of a potent plasma thromboplastin are a platelet factor (or factors), anti-haemophilic globulin, Factor V, Factor VII, and Christmas factor. Of these, Factor VII and the Christmas factor are predominantly serum factors, although the latter also exists in plasma. Platelet numbers and function were not studied in this investigation, but previous studies by one of us (W. N. B.) suggest that a platelet factor is not the principal site of action of aureomycin. Reversal of the aureomycin effect by increasing the concentration of platelet-free alumina plasma or platelet-free serum also suggests that we are concerned rather with a substance in serum, and to a minor extent in alumina plasma, than with a platelet factor. The constancy of the one-stage prothrombin time, both in the normal and in a patient with a Factor VII deficiency, demonstrates that Factor VII is not the responsible serum component. The correction of the aureomycin post-administration thromboplastin generation curve with sera other than that of Christmas disease, and the accentuation of the abnormal tests in a patient with Christmas disease, suggests that 
this component is primarily involved in the action of aureomycin; the effect is apparently exerted by inhibition of the Christmas factor, since increasing the concentration of the plasma or serum abolishes it to a varying degree. No such acquired deficiency of Christmas factor has been reported to date.

The results with terramycin are difficult to interpret. Although the tendency seems to be slightly towards hypercoagulability in the normal, no significant effect occurs in the presence of hypothromboplastinaemia. Were the former significant, it would be expected that a clinical predisposition to thrombosis would have been reported by this time; we are not aware of any such report up to the present.

Though technically significant, these studies do not indicate any serious impairment of the normal coagulation mechanism by any of the drugs considered. This is not the case, however, where there is already a defect in the generation of plasma thromboplastin due to a deficiency of Christmas factor. In other hypothromboplastinaemic states, the position appears to be more akin to that in the normal subject. A therapeutic dilemma from this cause should therefore be quite rare, save for the specialist in coagulation problems.

There are obviously many aspects of this question which require fuller investigation, such as the relation of these findings to the route of administration, duration of administration, and size of dose. This preliminary report is meant simply as a suggestive guide to a more promising technical approach than is offered by the simpler tests alone.

\section{Summary}

During study in vitro and in vivo of the effect of several antibiotics on blood coagulation, no evidence of hypercoagulability was found, except with terramycin, and its effect was doubtfully significant. Although other minor effects were observed on the coagulation mechanism of normal subjects, it was not felt that these had any clinical implications.

No significant change occurred in the prothrombin complex with any of the antibiotics studied. Aureomycin, and to a minor degree chloromycetin and probably erythromycin, impaired thromboplastin generation, apparently by reducing the effective level of circulating Christmas factor. Terramycin and penicillin had no deleterious effect on thromboplastin generation.

Preliminary studies, in hypothromboplastinaemic conditions, suggest that aureomycin and chloromycetin may significantly aggravate the defect of Christmas disease.

We are grateful to Sir Lionel Whitby, Regius Professor of Physic, and to Dr. F. G. J. Hayhoe for providing facilities and encouragement for this work, which was supported by the Elisabeth Storey Fund. Invaluable technical help was given by Miss S. C. Tomlin, and Messrs. B. W. Gurner and R. J. Flemans prepared the graphs for publication.

\section{REFERENCES}

Bell, W. N., and Alton, H. G. (1954). Nature, 174, 880.

Biggs, R., and Douglas, A. S. (1953). Journal of Clinical Pathology, 6, 23 .

- - and Macfarlane, R. G. (1953). J. Physiol., Lond., 122, 538. Casassa, P. M. (1952). Minerva med., Torino (parte sci.), 43, (2), 55. Florey, H. W., and Jennings, M. A. (1949). In Antibiotics, vol. 2, p. 1218. Oxford University Press, London.

Galt, J., and Hunter, R. B. (1950). Amer. J. med. Sci., 220, 508. Macht, D. I. (1952). J. Amer. med. Ass., 148, 265.

Miller, M. A., and Bass, H. E. (1952). New York J. Med., 52, 1423. Parker, J. W., Jr., and Wright, L. T. (1952). Science, 116, 282. 